\title{
A single session with a roller massager improves hamstring flexibility in healthy athletes: a randomized placebo-controlled crossover study
}

\author{
Anna Folli ${ }^{1}$. Filippo Ghirlanda ${ }^{1} \cdot$ Corrado Cescon $^{1} \cdot$ Alessandro Schneebeli $^{1} \cdot$ Céline Weber $^{2} \cdot$ Patrick Vetterli $^{2,3,4}$. \\ Marco Barbero ${ }^{1}$ (D)
}

Received: 5 June 2020 / Accepted: 26 January 2021 / Published online: 15 February 2021

(c) The Author(s) 2021

\begin{abstract}
Purpose The aim of this randomized placebo-controlled crossover study was to compare the acute effect on young athletes of a single session of roller massager (RM) with that obtained from passive static stretching (PSS) and a placebo intervention (PL) on hamstring flexibility and on strength.

Methods Twenty-nine (23 male, 6 female) young athletes completed the study. Maximal voluntary contraction (MVC) and two-leg sit-and-reach test were performed before and immediately after PL, PSS and RM on three different days.

Results Results showed that all three interventions increased the flexibility of the hamstring muscles compared to the pre-test measurements (Wilcoxon signed-rank test, $p<0.05$ ). Only the RM intervention was significantly higher than the PL intervention (sham ultrasound). Stretching intervention was not significantly different from either of the other two interventions. None of the three interventions significantly changed the muscle strength in the short term.

Conclusions RM can be considered as an effective alternative to stretching to increase the flexibility of the hamstring. This could be meaningful when stretching is contraindicated or evokes pain.
\end{abstract}

Keywords Flexibility $\cdot$ Placebo $\cdot$ Self-myofascial release $\cdot$ Strength $\cdot$ Stretching

$\begin{array}{ll}\text { Abbreviations } \\ \text { MVC } & \text { Maximal voluntary contraction } \\ \text { PL } & \text { Placebo intervention } \\ \text { PSS } & \text { Passive static stretching } \\ \text { RM } & \text { Roller massager } \\ \text { ROM } & \text { Range of motion } \\ \text { SS } & \text { Static stretching }\end{array}$

Marco Barbero

marco.barbero@supsi.ch

1 Rehabilitation Research Laboratory 2rLab, Department of Business Economics, Health and Social Care, University of Applied Sciences and Arts of Southern Switzerland, SUPSI DEASS, Manno/Landquart, Switzerland

2 Centro Cantonale di Medicina dello Sport (CCMS), Ente Ospedaliero Cantonale (EOC), Tenero, Switzerland

3 Dipartimento Educazione Cultura e Sport (DECS), Bellinzona, Switzerland

4 Scuola Professionale per Sportivi d'élite Tenero (SPSE), Tenero, Switzerland

\section{Introduction}

In human anatomy, the hamstring muscles are significantly implicated in the lower limb kinematics and in posture [1]. The correct activation of this muscle group, alongside those of the quadriceps femoris and the support of the anterior cruciate ligament, is crucial in the swing phase of the gait cycle, the balance of the lower limb, and the position of the pelvis [1].

Posterior thigh strains are commonly observed in athletes of different disciplines [2] and are the most frequently observed injuries in high-level soccer players, representing $12-16.3 \%$ of all injuries [3-5] and $39.5 \%$ of all muscle strains [5]. Age, non-countermovement jump performance, and decreases in the range of motion ("ROM") with respect to hip and hamstring flexibility are among the possible risk factors for hamstring injuries [4, 6, 7]. Additionally, a recent study suggested that hamstring flexibility is not only a risk factor for posterior thigh muscle injuries but also a key factor corresponding to soccer-specific skills, such as sprinting, jumping, agility, and kicking [8].

Even though a general consensus among experts regarding risk factors for hamstring injuries is not currently 
available [2,9], and the efficacy of preventative interventions has not yet been established [10], several prior studies have proposed different training strategies with which to minimize the risks $[4,7,8,11,12]$. Athletes, sports trainers, and physiotherapists thus apply exercises protocols, including different stretching techniques [10]. The suggested rationale for prescribing stretching exercises, especially as part of preperformance routines, is related to the fact that the greater flexibility thereby obtained improves energy absorption during the lengthening of muscles. This can, in turn, reduce the risk of muscle strain injuries [13]—although some studies have found that sustained static stretching ("SS") may induce an acute reduction of performance [13-16].

Scientific and technical evolution in the field of stretching has also led to the development of specific devices aiming to enhance muscular performance and flexibility, among which the roller massager ("RM") is well-known. The RM stick is a dense foam cylinder with a wavy surface that therapists roll on the patients' body using two side handles. The user can utilize his/her body weight to modulate the pressure and the intensity of the massage.

Different investigations have confirmed that application of the RM can improve immediate post-application ROM [16-21]. Moreover, when used after exercise, it seems to reduce muscle soreness [17, 19, 20, 22, 23].

Most of the current evidence suggests that rolling does not seem to provide significant performance improvements [20], nor strength decrease [17, 18, 24-27]; but in some cases, a small positive effect on some performance and strength parameters has been found $[19,25,26]$.

To date, the underlying physiological mechanisms of RM are much discussed and have been attributed to several potential factors, including the adaptation of the compressed tissue and a neural adaptation response of the central nervous system [21, 28]. The local changes seem to include increased blood flow, improvements in vascular function and reductions of viscoelastic stiffness and of fluid viscosity [21]. In addition, Behm and Wilke [28] postulated the hypothesis that the release could be related to the stimulation of proprioceptors or to local hydration changes. The adaptation of the central nervous system, instead, seems to be associated to the function of the magnitude of receptors present in the soft tissues, especially Ruffini and Pacinian receptors, which can inhibit the sympathetic activity and lead to muscle relaxation [21]. Also interstitial type III and IV receptors (pain, tension and pressure receptors) seems to be involved [21]. Moreover, the stimulation of parasympathetic nervous system and the ischemic compression with the rolling massage seem to play a role in the decreased pain perception [21].

To our knowledge, only a few studies on roller massager have included a placebo-treated group [29, 30], and any of them was conducted on hamstring muscles.
The aim of the present study was to compare the acute effect on young athletes of a single session of RM with that obtained from passive static stretching ("PSS") and a placebo intervention ("PL") on hamstring flexibility and on strength. It was hypothesized that both interventions would improve ROM. Moreover, we expected that, unlike the RM, PSS would reduce maximal force.

\section{Methods}

This was a randomized placebo-controlled crossover study, designed to assess the immediate post-treatment effects of the RM on muscle flexibility in healthy athletes. The study was conducted in a sport center in Switzerland between February and March 2016.

\section{Participants}

The protocol was approved by the local ethical committee (ID 3013-2016-00017) and all procedures were followed in accordance with the Declaration of Helsinki. All subjects signed an informed consent prior to testing.

Based on preliminary measures of maximal voluntary contraction (MVC) and hamstring extensibility in healthy subjects [31,32], the sample size required to achieve a statistical power of $1-\beta=0.80$ at the level $\alpha=0.05$ amounted to 30 patients, with a minimum detectable difference of about $1 \mathrm{~cm}$ and $10 \mathrm{Nm}$. To ensure this number of participants for the statistical analysis, 38 young healthy athletes (31 male, 7 female) were recruited from a local sports training school. The mean $( \pm$ SD) age, height, and weight were 16 years old $( \pm 1.14$ years $), 176.7 \mathrm{~cm}( \pm 7.8 \mathrm{~cm})$, and $68.6 \mathrm{~kg}( \pm 10.2 \mathrm{~kg})$, respectively.

The inclusion criteria were specified as follows: no history of hamstring injury in the last 12 months and an absence of any painful conditions of the musculoskeletal system. Furthermore, the exclusion criteria were as follows: surgery of the lower limbs or spine in the last 12 months; history of connective tissue, metabolic, or endocrine diseases; systemic inflammatory disorders; rheumatoid arthritis; or spondyloarthropathy.

\section{Procedures}

Three selected interventions were performed on three different days with at least two days in between, to allow washout periods and avoid carryover effects [18]. Prior to the intervention, subjects had the opportunity to try the testing procedures and underwent 5 min warm-up of cycling, maintaining a pace of about 80 revolutions per minute with a low to moderate resistance. Then, baseline measures of MVC and flexibility (sit-and-reach test) of the hamstring and 
lower back were performed. After these measurements were taken, subjects underwent one of the following interventions on both legs: RM, PSS, or a PL. The order of the three interventions was randomized for each participant. Following completion of the application of the intervention, MVC and hamstring flexibility results were reacquired (post-test). Participants were asked to maintain the same activity level across the duration of the study.

\section{Measurements: MVC and hamstring flexibility}

An MVC of the right leg was performed with the participant sitting in an ergometer (COR1; OT Bioelettronica, Turin, Italy), consisting of an ergonomic chair equipped with a load cell operating linearly in the range $0-1000 \mathrm{~N}$ (Mod. TF2/S; CCT Transducers, Turin, Italy). The force signal detected by the load cell was amplified (bandwidth $=0-80 \mathrm{~Hz}$ ) (MISOII; OT Bioelettronica, Turin, Italy). The subject's knee was maintained with a flexion of $90^{\circ}$, and subjects were verbally pushed to reach their maximal force flexing their knee and to maintain it for a plateau of about $2 \mathrm{~s}$. The force signal was shown on the MISO-II display, enabling the recording of the maximal force of the hamstring muscles within $5 \mathrm{~s}$. The test was repeated twice, with two minutes rest in between. The highest of the two MVC results was then considered for further analysis.

Subsequently, each participant underwent a sit-and-reach test: they sat with their legs extended forward and their feet resting against a special device, to measure the flexibility of their hamstring muscles (Modified Sit-and-Reach Test Box; Baseline Evaluation Instruments, Fabrication Enterprises, Inc., White Plains, New York, USA). To ensure an extended position of the knees, a belt was positioned over subject thighs and slightly tensioned. Participants were asked to flex slowly forward, holding their arms and fingers of their hands fully extended, until reaching their position of maximum elongation. This position was then maintained for at least $2 \mathrm{~s}$. The test was repeated three times with an interval of one minute in between each test, with the mean value of the three repetitions used for the analysis.

\section{Intervention: passive static stretching}

In the PSS intervention, participants lay supine in a relaxed position. While the researcher was flexing the leg of the subject, keeping the knee in full extension, the subject was asked to indicate the degree of perceived pain approximately every $5 \mathrm{~s}$ (through reference to the visual analog scale). The hamstring muscles of the participants were stretched to the point of discomfort. This position was maintained for $30 \mathrm{~s}$, as previously suggested by other authors [33-37]. To ensure the targeted stretching of the hamstring, each participant's pelvis was controlled and stabilized by the researcher, as suggested by Sullivan and colleagues [38]. The procedure was repeated twice on each leg.

\section{Intervention: roller massager}

In the RM intervention, participants lay in a prone position. The researcher massaged the rear compartment of both thighs using an RM (TheraBand ${ }^{\circledR}$; Akron, OH, USA), as shown in Fig. 1, for $60 \mathrm{~s}$ per leg. The duration of the RM's application was based on a prior pilot test, in which 12 participants were exposed to RM interventions of 7 different durations (from 5 to $180 \mathrm{~s}$ ). The internal pilot revealed that the majority of subjects obtained a maximum improvement in the sit-and-reach test score after they had been treated for a time between 30 and $90 \mathrm{~s}$. In the present study, during the massage, the researcher maintained a constant pressure of $13 \mathrm{~kg}$ on the thigh and a rhythm of $120 \mathrm{bpm}$ (1 cycle per second), as proposed by Sullivan and collaborators [18]. The constant pressure was assured through reference to visual feedback from a signal amplifier (MISO II; OT Bioelettronica, Turin, Italy) that transduced the signal of a dynamometer positioned under the therapy bed's legs (BAR1; OT Bioelettronica, Turin, Italy), calibrated at the beginning of the study. The constant rhythm was assured by

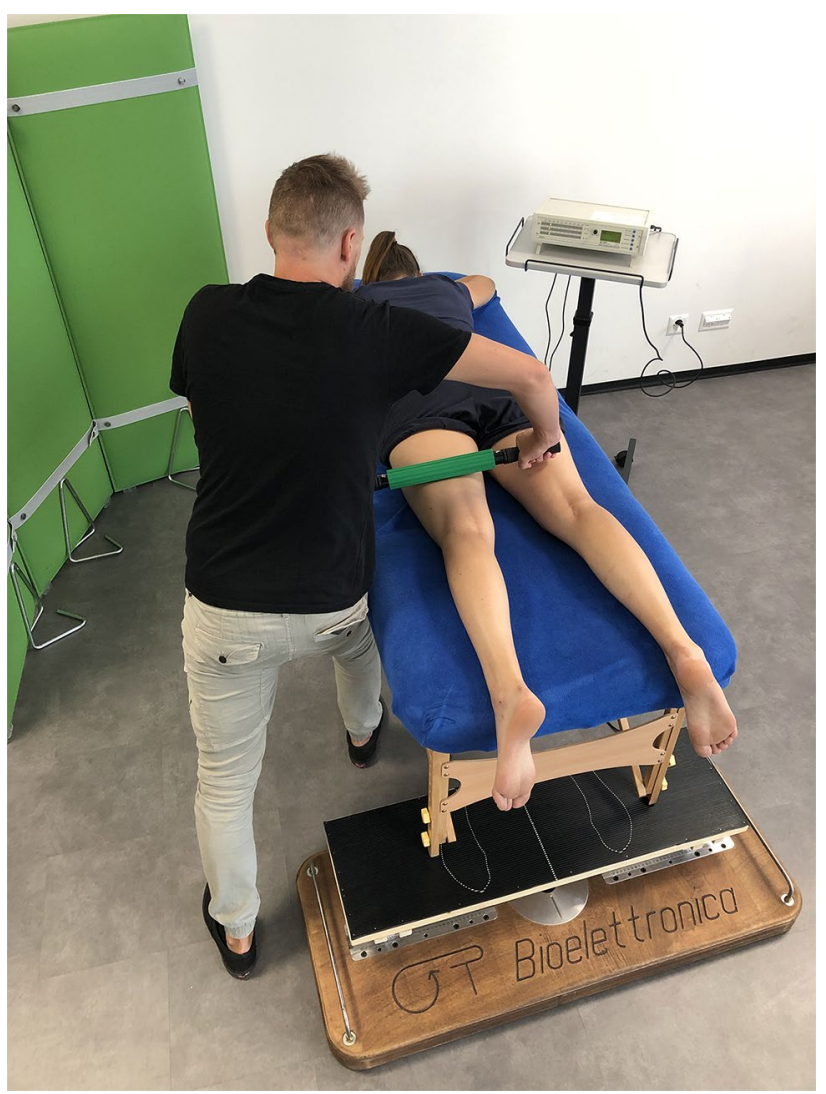

Fig. 1 Researcher practicing massage with roller massager (RM) 
a metronome. During the massage, the subject was asked to indicate the degree of perceived pain approximately every $5 \mathrm{~s}$ (again, using the visual analog scale). The application of RM was previously studied by Sullivan and colleagues [18] that extracted the parameters of the application of RM through the observation of experienced individuals using it. This makes the conditions of the present study and the parameters of the massage more similar to those of a clinical or sporting context and increases the generalizability of the results.

\section{Intervention: placebo intervention}

In the PL intervention, participants lay in a prone position. The researcher applied a treatment on the hamstring muscles with a non-functioning (it was turned off) ultrasound device for $60 \mathrm{~s}$ per leg. A discrete amount of gel was applied to make the placebo intervention more similar to a real ultrasound treatment. The participants did not know that the device had been turned off.

\section{Statistical methods}

Results of a Shapiro-Wilk normality test revealed that the distribution of data for flexibility and force significantly deviated from normality. Therefore, statistical analysis was performed using non-parametric tests for median values. The Friedman test and the Wilcoxon signed-rank test were performed to identify any differences in hamstring flexibility and force data recorded before and after the interventions. IBM SPSS Statistics 20.0.0 software (IBM, Segrate, Milan, Italy) was used to run statistical analyses. The significance level was set to $p<0.05$.

\section{Results}

Twenty-nine ( 23 male, 6 female) out of 38 athletes completed the study; their mean $( \pm$ SD) age, height, and weight were 16 years old $( \pm 1.23$ years), $176.2 \mathrm{~cm}( \pm 7.1 \mathrm{~cm})$, and $67.8 \mathrm{~kg}( \pm 11.1 \mathrm{~kg})$, respectively. Seven athletes did not attend the first session as well as the following one without providing any justification, and two others left the study because of muscle soreness that had occurred due to the training sessions of the previous days. The data for all other subjects were subsequently analyzed with a Wilcoxon signed-rank test. Descriptive statistics are reported in Table 1.

As shown in Fig. 2a, all three interventions increased the flexibility of the hamstring muscles compared to the pretest measurements (Wilcoxon signed-rank test, $p<0.05$ ). Comparing the increases in flexibility of subjects' hamstring between the three interventions (Fig. 2b), only the

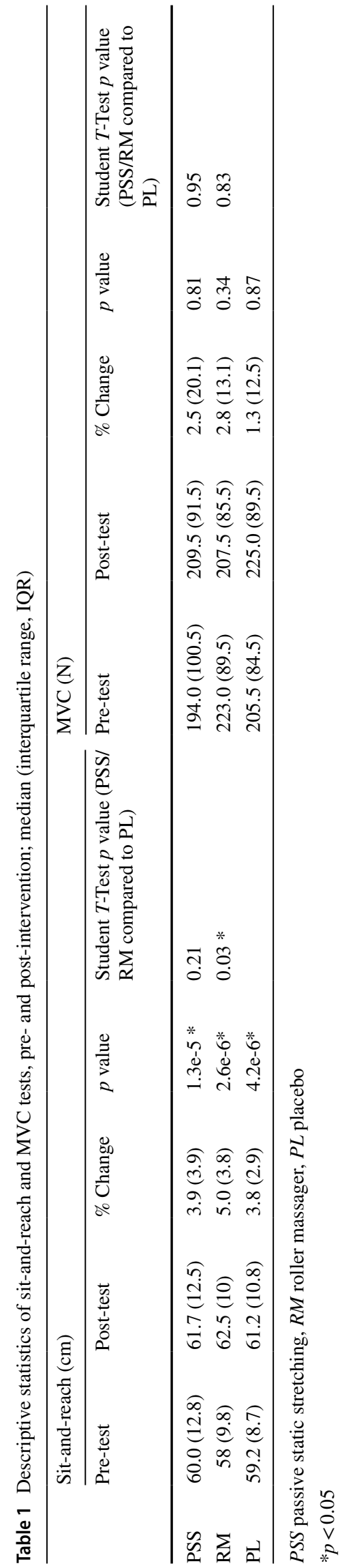


Fig. 2 a Measurements of sitand-reach recorded in the preand post-test for the three interventions; $\mathbf{b}$ reaching differences observed between pre- and post-test for the three interventions. $* p<0.05, * * p<0.01$. PSS passive static stretching, $R M$ roller massager, $P L$ placebo
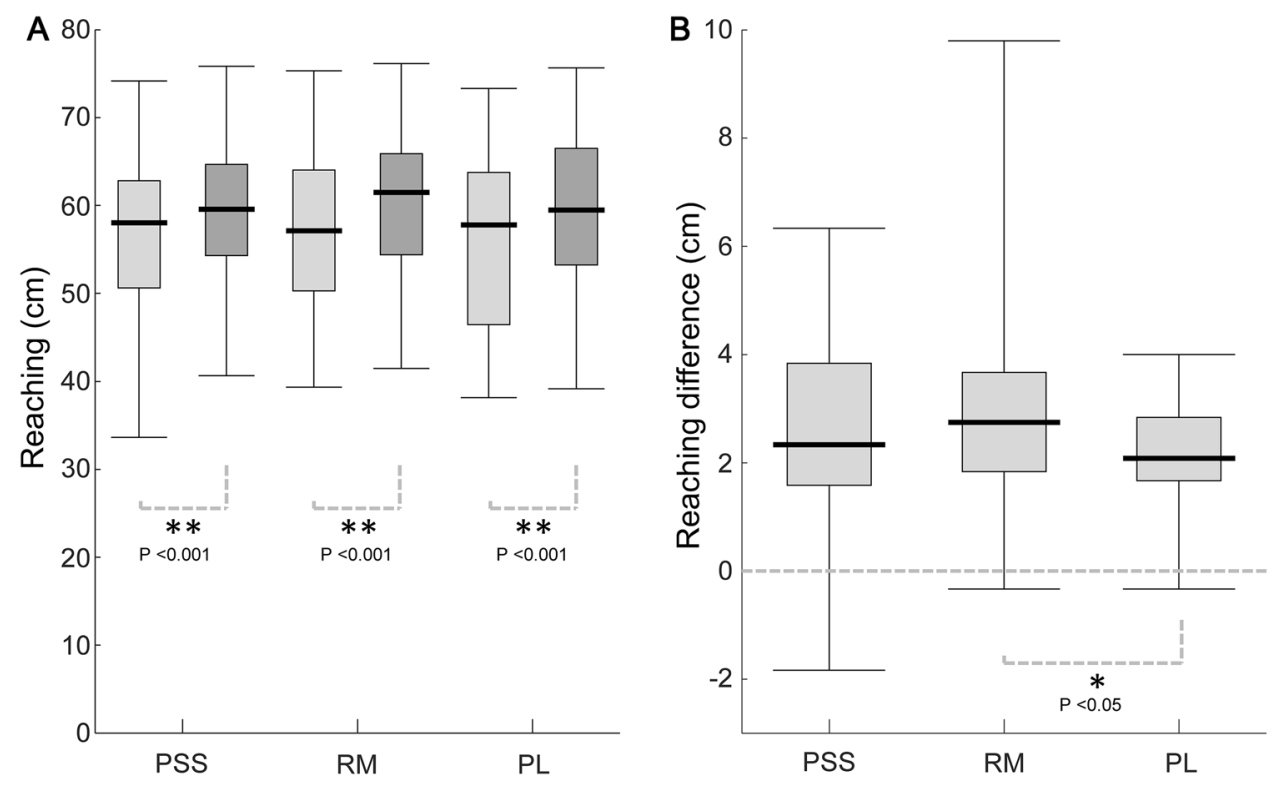

RM intervention was significantly higher than the PL intervention (i.e., sham ultrasound). The stretching intervention was not significantly different from either of the other two interventions.

Additionally, none of the three interventions changed significantly the muscle strength (i.e., as measured through MVC) in the short term.

\section{Discussion}

The purpose of this study was to compare the immediate effect on young athletes of a single session of RM (versus PSS and PL) on their hamstring muscles' flexibility and strength. The study's results suggest that PSS, RM, and PL interventions all increase hamstring muscles flexibility straightaway, but only the improvement related to RM intervention was found to be significantly higher compared to the PL intervention. Moreover, according to our results, none of the considered interventions had a significant acute effect on MVC.

RM intervention showed an immediate effect on hamstring flexibility, with a significant increase in the sit-andreach test scores compared to the PL intervention. Our findings are similar to those of Sullivan and colleagues [18], who compared a group of healthy participants undergoing four different durations of RM ( 1 set of $5 \mathrm{~s}, 1$ set of $10 \mathrm{~s}, 2$ sets of $5 \mathrm{~s}$, and 2 sets of $10 \mathrm{~s}$ ) to a control group (no intervention). In that study, the subjects had to perform a singleleg sit-and-reach test for ROM, an MVC force test, and a measure of muscle activation of the biceps femoris (electromyography) for the muscle strength. The authors found an increase in the hamstring ROM up to $4.3 \%$, with no change in MVC and EMG activity. Moreover, their results seem to indicate that there is a time-related effect between RM intervention exposure and increases of muscle flexibility. The improvement in ROM found in our study was 5\%. This slightly different result could be attributed to the different population (young athletes, instead of recreationally active persons), the alternative testing modalities (two-legged sitand-reach test, instead of a single-leg test), or the different duration of the intervention ( $60 \mathrm{~s}$, instead of a maximum of $20 \mathrm{~s}$ ). Our findings could be considered as an evolution of the findings of Sullivan et al. [18], suggesting that a prolonged RM intervention can lead to an augmented acute increase of ROM, without affecting the muscular performance. However, findings from our pilot test suggested that the maximum increase in flexibility is reached between 30 and $90 \mathrm{~s}$ of treatment, and a longer exposure did not further augment muscle flexibility.

Conversely, Monteiro and colleagues [39] compared four self-massage interventions, differentiated in terms of type of massage and volume of exposure. In their study, selfmassage of the hamstring resulted in increased short-term hip flexion and extension ROM, which became more evident with higher dose volumes. Monteiro et al. [39] strengthened the hypothesis of time- and dose-related change in ROM for longer interventions as well. However, the RM was selfapplied and the pressure was not controlled. Differences in time- and dose-related change could therefore be attributed to the different treatment intensities.

In addition, studies conducted on other muscles have found similar increases in muscle flexibility. Among these, Halperin and colleagues [25] studied the effect on passive ankle ROM, MVC, and balance of static stretching ("SS") and self-massage with a RM on the calf muscles. They found 
that both interventions increased ankle ROM at 0 and $10 \mathrm{~min}$ after exposure to the intervention. Moreover, they found that RM led to a small improvement in MVC at 10-min post-intervention.

To our knowledge, no previous studies on roller massager on hamstring have included a placebo-treated group applied to the target muscles. However, Phillips et al. [29] and Griefahn et al. [30] investigated the effect of rolling and a placebo intervention on the flexibility and performance of quadriceps and triceps surae muscles and of the thoracolumbar fascia, respectively. Similar to our results, both studies found an increase of flexibility of the target muscles/fascia $[29,30]$. Contrary to our findings, though, Phillips and colleagues [29] found a negative effect of $5 \mathrm{~min}$ of rolling on muscle performance.

PSS intervention showed an acute increase of hamstring flexibility, but the effect was not superior to that from the placebo intervention. The results of our study do not totally share those found in previous studies. In fact, more studies have affirmed that SS of hamstring muscles is effective in increasing their flexibility [14, 40-42]. For example, Michaeli and colleagues [43] examined the effect of two different stretching interventions and a placebo intervention on hamstring flexibility, immediately after the intervention and 1-h post-intervention. In contrast to our results, they found that SS intervention is effective in enhancing acute hamstring flexibility, compared to a placebo intervention. The difference between our results and those of Michaeli's group could be attributed to the different population, the different testing modalities, or even the different placebos. In fact, as the authors underline [43], the placebo that was applied in their study (a sham ultrasound on the dorsal face of the foot) was not properly blinded to the participants. Conversely, the participants of our study believed that they were receiving a treatment on their hamstring muscles.

Kataura and colleagues [14] studied the effect of SS on hamstring muscle flexibility and muscle force in relation to the application intensity. The authors defined the stretching intensity with a percentage of the ROM recorded at the point of maximum tolerable intensity of stretching without pain. They pointed out that only stretching interventions with an intensity greater than $80 \%$ significantly increase hamstring flexibility. Moreover, they found that with $100 \%$ and $120 \%$ intensity of stretching, there is a significant reduction of isometric muscle force [14].

Our PSS intervention was in line with that of Kataura et al. in terms of intensity and/or time. Therefore, the differences between our results and theirs could be attributed to different study populations, different testing modalities, or even the presence of a placebo in our study.

To our knowledge, no prior studies have compared the effect of SS with that of an RM on hamstring muscles. The only study featuring SS and RM on hamstring muscles is that of Hodgson et al. [42], which combined the two techniques and compared the effect on hamstring flexibility and performance of SS alone and of SS with one or more adjunctive treatments with RM. The authors concluded that SS increases flexibility, and that the addition of RM makes the change more significant or prolongs it over time [42]. Their results also suggest that SS reduces muscle performance whereas the addition of RM does not influence it [42].

Our results are in contrast with those of this earlier study. Although we tried to standardize the application of the stretching procedure (i.e., reporting the degree of perceived pain and maintaining a stretching duration in line with those proposed in the literature), we cannot exclude that our application was under-dosed. Moreover, we used different testing modalities and included a placebo-treatment to compare with the interventions.

Our results also showed that the group treated with the sham ultrasound increased the flexibility of their hamstring muscles, supporting the "placebo effect" already reported in previous trials $[44,45]$. The observed improvement may be explained by positive expectations associated to the placebo ultrasound intervention.

The magnitude of the improvement and the non-significant difference with PSS may appear surprising, but the nature of the outcome measure should be considered. The sit-and-reach test score can be influenced by the subject's performance and by painful sensations, while the central pain-modulatory systems activated by the placebo effect can play a role too. Additionally, the control group underwent a placebo-treatment. Therefore, the between group differences represent the real effect of the interventions, since both treatments increased the sit-and-reach value.

\section{Limitations}

The present study has a number of limitations that must be considered when interpreting the results. First, the sit-andreach test is not specific, and did not allow us to discriminate the flexibility of hamstring muscles from the flexibility of the lumbar spine of participants. Although we treated the hamstring bilaterally and we did not perform interventions on the lumbar spine, even if we could hypothesize that the changes seen in the test were attributable to changes in hamstring flexibility, and acknowledging that the sit-andreach test shows a high reliability [31], we cannot exclude the influence of other factors. Moreover, the enhancement of flexibility observed in our study could be attributed to the repetition of the testing modalities. Participants were asked to repeat the sit-and-reach test three times pre-intervention and three times post-intervention, which could have affected the viscoelastic properties of their tissues and enhanced the ROM of their hips. 
Second, the population of this study included young athletes of which we did not record the level of activity and who practice different sports. The variability of these sports could influence the differences of physical and biological features of the participants and subsequently their results. This diversity is not only a limitation, though, because it better represents the variability of the population of athletes with whom a clinician, a fitness instructor, or a trainer can work.

In addition, the RM used in the study was designed for self-massage, which could bring about more variability and less standardization of the treatment. The results could be therefore less reliable if the device is managed and used by the individuals themselves.

\section{Conclusions}

The RM can be considered as an effective alternative to stretching to increase the acute flexibility of the hamstring, especially in cases in which stretching is contraindicated or evokes pain.

Further studies are needed to increase knowledge about RM and the possibility of proposing it as a method to improve muscle flexibility.

Acknowledgements The authors would like to thank the Yellow $\mathrm{P}$ Foundation.

Funding Open Access funding provided by SUPSI - University of Applied Sciences and Arts of Southern Switzerland. This study was support in part by a scholarship from the Yellow P Foundation. The authors report no conflict of interest.

Data availability The datasets generated during and/or analyzed during the current study are available from the corresponding author on reasonable request.

\section{Compliance with ethical standards}

Conflict of interest The authors report no conflict of interest.

Ethical approval The protocol was approved by the local ethical committee (ID 3013-2016-00017) and all procedures were followed in accordance with the Declaration of Helsinki.

Informed consent All subjects signed an informed consent prior to testing.

Open Access This article is licensed under a Creative Commons Attribution 4.0 International License, which permits use, sharing, adaptation, distribution and reproduction in any medium or format, as long as you give appropriate credit to the original author(s) and the source, provide a link to the Creative Commons licence, and indicate if changes were made. The images or other third party material in this article are included in the article's Creative Commons licence, unless indicated otherwise in a credit line to the material. If material is not included in the article's Creative Commons licence and your intended use is not permitted by statutory regulation or exceeds the permitted use, you will need to obtain permission directly from the copyright holder. To view a copy of this licence, visit http://creativecommons.org/licenses/by/4.0/.

\section{References}

1. Stępień K, Śmigielski R, Mouton C et al (2019) Anatomy of proximal attachment, course, and innervation of hamstring muscles: a pictorial essay. Knee Surg Sports Traumatol Arthrosc Off J ESSKA 27(3):673-684

2. Opar DA, Williams MD, Shield AJ (2012) Hamstring strain injuries: factors that lead to injury and re-injury. Sports Med 42(3):209-226

3. Ekstrand J, Hagglund M, Walden M (2011) Injury incidence and injury patterns in professional football: the UEFA injury study. Br J Sports Med 45(7):553-558

4. Henderson G, Barnes CA, Portas MD (2010) Factors associated with increased propensity for hamstring injury in English Premier League soccer players. J Sci Med Sport 13(4):397-402

5. Jones A, Jones G, Greig N, Bower P, Brown J, Hind K, Francis P (2019) Epidemiology of injury in English Professional Football players: a cohort study. Phys Ther Sport 35:18-22

6. Wan X, Qu F, Garrett WE, Liu H, Yu B (2017) Relationships among hamstring muscle optimal length and hamstring flexibility and strength. J Sport Health Sci 6(3):275-282

7. Witvrouw E, Danneels L, Asselman P, D'Have T, Cambier D (2003) Muscle flexibility as a risk factor for developing muscle injuries in male professional soccer players: a prospective study. Am J Sports Med 31(1):41-46

8. García-Pinillos F, Ruiz-Ariza A, Moreno del Castillo R, LatorreRomán PÁ (2015) Impact of limited hamstring flexibility on vertical jump, kicking speed, sprint, and agility in young football players. J Sports Sci 33(12):1293-1297

9. Foreman TK, Addy T, Baker S, Burns J, Hill N, Madden T (2006) Prospective studies into the causation of hamstring injuries in sport: a systematic review. Phys Ther Sport 7(2):101-109

10. Goldman EF, Jones DE (2010) Interventions for preventing hamstring injuries. Cochrane Database Syst Rev

11. Rey E, Padrón-Cabo A, Barcala-Furelos R, Mecías-Calvo M (2016) Effect of high and low flexibility levels on physical fitness and neuromuscular properties in professional soccer players. Int J Sports Med 37(11):878-883

12. Ribeiro-Alvares JB, Dornelles MP, Fritsch CG, de Lima-e-Silva FX, Medeiros TM, Severo-Silveira L, Marques VB, Baroni BM (2019) Prevalence of hamstring strain injury risk factors in professional and under-20 male football (Soccer) players. J Sport Rehabil 1-23

13. Behm DG, Blazevich AJ, Kay AD, McHugh M (2016) Acute effects of muscle stretching on physical performance, range of motion, and injury incidence in healthy active individuals: a systematic review. Appl Physiol Nutr Metab 41(1):1-11

14. Kataura S, Suzuki S, Matsuo S, Hatano G, Iwata M, Yokoi K, Tsuchida W, Banno Y, Asai Y (2017) Acute effects of the different intensity of static stretching on flexibility and isometric muscle force. J Strength Cond Res 31(12):3403-3410

15. Barbosa GM, Trajano GS, Dantas GAF, Silva BR, Vieira WHB (2019) Chronic effects of static and dynamic stretching on hamstrings eccentric strength and functional performance: a randomized controlled trial. J Strength Cond Res

16. Sağiroğlu İ, Kurt C, Pekünlü E, Özsu İ (2017) Residual effects of static stretching and self-myofascial-release exercises on flexibility and lower body explosive strength in well-trained combat athletes. Isokinet Exerc Sci 25(2):135-141 
17. MacDonald GZ, Button DC, Drinkwater EJ, Behm DG (2014) Foam rolling as a recovery tool after an intense bout of physical activity. Med Sci Sports Exerc 46(1):131-142

18. Sullivan KM, Silvey DBJ, Button DC, Behm DG (2013) Rollermassager application to the hamstrings increases sit-and-reach range of motion within five to ten seconds without performance impairments. Int J Sports Phys Ther 8(3):228-236

19. Wiewelhove T, Döweling A, Schneider C, Hottenrott L, Meyer T, Kellmann M, Pfeiffer M, Ferrauti A (2019) A meta-analysis of the effects of foam rolling on performance and recovery. Front Physiol 10

20. Hughes GA, Ramer LM (2019) Duration of myofascial rolling for optimal recovery, range of motion, and performance: a systematic review of the literature. Int J Sports Phys Ther 14(6):845-859

21. Wilke J, Müller A-L, Giesche F, Power G, Ahmedi H, Behm DG (2020) Acute effects of foam rolling on range of motion in healthy adults: a systematic review with multilevel meta-analysis. Sports Med 50(2):387-402

22. Cavanaugh MT, Döweling A, Young JD, Quigley PJ, Hodgson DD, Whitten JHD, Reid JC, Aboodarda SJ, Behm DG (2017) An acute session of roller massage prolongs voluntary torque development and diminishes evoked pain. Eur J Appl Physiol 117(1):109-117

23. Cheatham SW, Kolber MJ, Cain M, Lee M (2015) The effects of self-myofascial release using a foam roll or roller massager on joint range of motion, muscle recovery, and performance: a systematic review. Int J Sports Phys Ther 10(6):827-838

24. Grabow L, Young JD, Alcock LR, Quigley PJ, Byrne JM, Granacher U, Škarabot J, Behm DG (2018) Higher quadriceps roller massage forces do not amplify range-of-motion increases nor impair strength and jump performance. J Strength Cond Res 32(11):3059-3069

25. Halperin I, Aboodarda SJ, Button DC, Andersen LL, Behm DG (2014) Roller massager improves range of motion of plantar flexor muscles without subsequent decreases in force parameters. Int $\mathrm{J}$ Sports Phys Ther 9(1):92-102

26. Peacock CA, Krein DD, Silver TA, Sanders GJ, Von Carlowitz K-PA (2014) An acute bout of self-myofascial release in the form of foam rolling improves performance testing. Int J Exerc Sci 7(3):202-211

27. Richman ED, Tyo BM, Nicks CR (2019) Combined effects of self-myofascial release and dynamic stretching on range of motion, jump, sprint, and agility performance. J Strength Cond Res 33(7): 1795

28. Behm DG, Wilke J (2019) Do self-myofascial release devices release Myofascia? Rolling mechanisms: a narrative review. Sports Med 49(8):1173-1181

29. Phillips J, Diggin D, King DL, Sforzo GA (2018) Effect of varying self-myofascial release duration on subsequent athletic performance. J Strength Cond Res

30. Griefahn A, Oehlmann J, Zalpour C, von Piekartz H (2017) Do exercises with the Foam Roller have a short-term impact on the thoracolumbar fascia? A randomized controlled trial. J Bodyw Mov Ther 21(1):186-193
31. Ayala F, de Baranda PS, De Ste Croix M, Santonja F (2012) Absolute reliability of five clinical tests for assessing hamstring flexibility in professional futsal players. J Sci Med Sport 15(2):142-147

32. Wells KF, Dillon EK (1952) The sit and reach-a test of back and leg flexibility. Res Q Am Assoc Health Phys Educ Recreat 23(1):115-118

33. Ayala F, de Baranda Andújar PS (2010) Effect of 3 different active stretch durations on hip flexion range of motion. J Strength Cond Res 24:430-436

34. Bandy WD, Irion JM (1994) The effect of time on static stretch on the flexibility of the hamstring muscles. Phys Ther 74:845-850

35. Bandy WD, Irion JM, Briggler M (1997) The effect of time and frequency of static stretching on flexibility of the hamstring muscles. Phys Ther 77:1090-1096

36. Cipriani D, Abel B, Pirrwitz D (2003) A comparison of two stretching protocols on hip range of motion: implications for total daily stretch duration. J Strength Cond Res 17:274-278

37. Decoster LC, Cleland J, Altieri C, Russell P (2005) The effects of hamstring stretching on range of motion: a systematic literature review. J Orthop Sports Phys Ther 35:377-387

38. Sullivan MK, Dejulia JJ, Worrell TW (2012) Effect of pelvic position and stretching method on hamstring muscle flexibility. Med Sci Sports Exerc 24:1383-1389

39. Monteiro ER, Cavanaugh MT, Frost DM, da Novaes Silva J (2017) Is self-massage an effective joint range-of-motion strategy? A pilot study. J Bodyw Mov Ther 21(1):223-226

40. Ahmed H, Iqbal A, Anwer S, Alghadir A (2015) Effect of modified hold-relax stretching and static stretching on hamstring muscle flexibility. J Phys Ther Sci 27(2):535-538

41. Cini A, de Vasconcelos GS, Lima CS (2017) Acute effect of different time periods of passive static stretching on the hamstring flexibility. J Back Musculoskelet Rehabil 30(2):241-246

42. Hodgson DD, Quigley PJ, Whitten JHD, Reid JC, Behm DG (2019) Impact of 10-minute interval roller massage on performance and active range of motion: J Strength Cond Res 1

43. Michaeli A, Tee JC, Stewart A (2017) Dynamic oscillatory stretching efficacy on hamstring extensibility and stretch tolerance: a randomized controlled trial. Int J Sports Phys Ther 12(3):305-313

44. Costa LOP, Maher CG, Latimer J, Hodges PW, Herbert RD, Refshauge KM, McAuley JH, Jennings MD (2009) Motor control exercise for chronic low back pain: a randomized placebo-controlled trial. Phys Ther 89(12):1275-1286

45. Goren A, Yildiz N, Topuz O, Findikoglu G, Ardic F (2010) Efficacy of exercise and ultrasound in patients with lumbar spinal stenosis: a prospective randomized controlled trial. Clin Rehabil 24(7):623-631

Publisher's Note Springer Nature remains neutral with regard to jurisdictional claims in published maps and institutional affiliations. 